\title{
Uma década de WhatsApp: novas rotinas de produção possibilitam o zapkeeper e o newsmaking da audiência
}

\section{A decade of WhatsApp: New production routines enable zapkeeper and audience newsmaking}

Recibido: 08/07/2019

Aceptado: 07/10/2019

Publicado: 05/12/2019
Lilian Saback de Sá Moraes liliansaback@puc-rio.br

Pontifícia Universidade Católica do Rio de Janeiro

(Brasil)

Resumen: Este artículo propone una observación cercana hacia el periodismo de la era del WhatsApp, a partir del seguimiento del programa del "Jornal BandNews Rio - $1^{\text {a }}$ Edição", programa de radio en directo, transmitido del 8 al 12 de abril de 2019. Desde la perspectiva de investigadores como Lage (2001), Traquina (2005), Castells (2015), Wolf (1985) y Aguiar (2014), el estudio se centra en teorías clásicas como el newsmaking y el gatekeeper aplicado en los tiempos contemporáneos. En conclusión, se identifican cambios en las rutinas de los profesionales de la prensa que hacen posible pensar en el surgimiento de zapkeeper y de newsmaking en la audiencia.

Palabras clave: WhatsApp, BandNews, Periodismo, Gatekeeper, Newsmaking.

Abstract: This paper proposes a close observation for journalism in the era of Whats App from the follow up of the program from April 8 to 12, 2019 of "Jornal BandNews Rio $-1^{a}$ Edição", a radio news programme. From the thinking of researchers such as Lage (2001), Traquina (2005), Castells (2015), Wolf 
(1985) and Aguiar (2014), the study strains around classic theories such as newsmaking and gatekeeper in contemporary times. In conclusion, it presents the changes in the routines of press professionals that make it possible to think about the emergence of zapkeeper and audience newsmaking.

Key words: WhatsApp, BandNews, Journalism, Gatekeeper, Newsmaking.

\section{Introdução}

O aplicativo WhatsApp completou 10 anos de existência em fevereiro de 2019, comemorando a fama de vedete das mudanças no circuito da informação. Segundo a Global Digital Report 2019 4,388 bilhões de pessoas no mundo usam a internet, sendo que mais de 3 bilhões delas movimentam as redes sociais (We are Social, 2019). No Brasil, a pesquisa identificou que 140 milhões de pessoas, $66 \%$ da sua população ativa na internet, é usuária das redes sociais e que, desse total, $89 \%$ usam o aplicativo para troca de mensagens (Pag Brasil, 2019).

Os jornalistas também aderiam à nova forma de enviar e receber texto, áudio e vídeo. Com o WhatsApp, os jovens profissionais de imprensa estão, por exemplo, acostumando-se a fazer uma entrevista, a essência do jornalismo (Altman, 1995), à distância, sem olhar nos olhos do entrevistado. O que pode ser um facilitador, pode ser também um sinal de alerta para as mudanças na rotina do ofício que por anos garantiu universalmente a credibilidade com base em boa apuração e checagem da informação.

Este artigo propõe investigar os prós e contras das novas tecnologias e a criação de novos ecossistemas midiáticos (Canavilhas, 2010), com os quais o profissional e a audiência compartilham a produção do conteúdo. Para amparar este debate, escolheu-se o apoio teórico prioritário dos mestres Nilson Lage e Nelson Traquina e um estudo de caso da programação do radiojornalismo produzido pela emissora brasileira BandNews FM no Rio de Janeiro. Lage porque fez o percurso da prática para a teoria como poucos; Traquina por ser um teórico consolidado no estudo das teorias do jornalismo; e o rádio por ter se reinventado diante das plataformas disponíveis na atual sociedade em rede (Castells, 2003). 
Este artigo acompanha, ainda, o pensamento de trabalhos recentes como de Luiz Custódio da Silva e Jeferson Luís Pires Rocha, que analisa a participação do ouvinte no "Jornal da CBN", veiculado pela rádio CBN São Paulo. Apesar de analisar a produção feita em uma emissora concorrente e para um jornal na capital paulista, observa a participação do público por meio do aplicativo. O estudo traz entre suas conclusões, por exemplo, que o WhatsApp reforça o papel do rádio como prestador de serviço.

Com tal ferramenta de baixo custo e alta agilidade, o ouvinte tem condições de chamar atenção para problemas que interferem na vida dele e que merecem ser veiculados por também interferir na vida de um número maior de pessoas que é ouvinte da rádio (Da Silva, Rocha \& Pires, 2015, p. 134).

E que na CBN a informação que chega por WhatsApp sempre é legitimada por um profissional: "uma característica importante na forma de apresentação do conteúdo que, na maioria dos casos, seguem acompanhados de ratificação por parte de jornalistas que estão na redação, na rua ou a bordo do helicóptero" (Da Silva, Rocha \& Pires, 2015, p. 134).

A rádio BandNews FM é referência no jornalismo local brasileiro, principalmente no Rio de Janeiro, por ser a praça com mais programas de notícias sobre a cidade. Durante a produção deste artigo eram quatro: "Notícias da Manhã", das $5 \mathrm{~h}$ às $7 \mathrm{~h}$, com Mario Dias Ferreira e Francini Augusto e uma pauta voltada para prestação de serviço (trânsito, previsão do tempo e transporte público); "Jornal BandNews Rio 1 ${ }^{a}$ Edição", das 9h às 11h, com Rodolfo Schneider e Agatha Meirelles; "Jornal BandNews Rio 2a Edição", das $17 \mathrm{~h}$ às $18 \mathrm{~h} 30$, com Marcus Lacerda e Isabele Rangel: e "Jornal BandNews Rio $3^{\mathrm{a}}$ Edição", às 20h30, com Pedro Antônio Guimarães (BandNews FM, 2019a).

O corpus do estudo faz parte de uma base de dados que venho investigando e foi obtido na seção de vídeos da página do Facebook da BandNews do Rio de Janeiro (BandNews FM, 2019b). Para a análise foi selecionado o material disponível sobre a semana de 8 a 12 de abril de 2019 do "Jornal BandNews

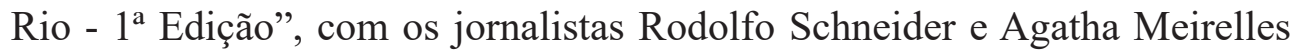
e, acompanhando e filtrando as mensagens do WhatsApp, a estagiária Julia Kallembach. Optou-se por este período porque foi uma semana em que ocorreram três fatos importantes na cidade: o fuzilamento do músico Evaldo Rosa 
dos Santos e do catador de materiais recicláveis Luciano Macedo por militares (Globo.com, 2019a); a maior chuva em 22 anos no Rio, que que causou a morte de dez pessoas (Globo.com, 2019b); e o desabamento de dois prédios na Muzema, Comunidade na Zona Oeste da cidade (Globo.com, 2019c).

A partir da identificação da pauta principal de cada dia, fez-se o levantamento de todas as mensagens de ouvintes recebidas pelos produtores do programa por meio do aplicativo WhatsApp. Com este mapeamento, atentou-se para a forma pela qual o público intervia na produção do noticiário e qual postura estava sendo adotada pelo jornalista profissional ao lidar com uma informação fornecida pela sua audiência. Na sequência buscou-se repensar as teorias do gatekeeper e do newsmaking na análise da rotina do jornalista de rádio da contemporaneidade.

Como complemento de método para elaboração deste texto, a estagiária do "Jornal BandNews Rio - $1^{a}$ Edição", responsável pelo WhatsApp, Julia Kallembach, foi entrevistada. A solicitação da entrevista foi feita e, por escolha da própria entrevistada (mas porque não dizer por ironia), o depoimento foi concedido por meio de mensagens de áudio enviadas por WhatsApp.

\section{Do Gatekeeper ao ZapKeeper}

O "Jornal BandNews Rio - 1 a Edição" vai ao ar das 9h às 11h30, mas, desde às $7 \mathrm{~h}$ da manhã, a estagiária Julia Kallembach está no comando do WhatsApp da rádio. Kallembach (2019) explica que há trabalho antes de o programa começar porque o ouvinte quer participar: concordar ou discordar do âncora do horário, informar sobre o trânsito na cidade ou fazer alguma denúncia. A ela cabe responder a todas as mensagens enviadas e, em seguida, decidir quais vão se transformar em notícia. "Eu tenho que fazer um filtro do que é importante, do que vale para a produção do programa, o que vale para a gente fazer um apanhado maior e apurar mais e dar como pauta no programa”.

Ao receber essas informações e decidir o que fazer com elas, pode-se dizer que a estagiária está na função de um gatekeeper (White, 1993), tradicionalmente exercida por um jornalista com mais tempo de profissão. Historicamente, de uma forma geral no rádio, a decisão de uma notícia ir ao ar ocorre em um processo que tem três momentos fundamentais. 
a primeira passa pelas chefias, que decidem os acontecimentos que se vão cobrir; a segunda etapa passa pelo repórter no terreno, que selecciona a informação essencial, e nada mais que a essencial, para construir a notícia; e, por fim, o último gatekeeper, aquele que tem a última palavra, é o editor, que escolhe o que será emitido na rádio e em que lugar é que essa informação irá ser emitida, como tema principal ou secundário (Fernandes, 2011, p. 95).

A teoria clássica do gatekeeper formulada em 1950 por David Manning White, a partir do conceito de Kurt Lewin ${ }^{1}$ em um estudo de 1947, é fundamental para compreendermos os critérios que levam à seleção e à construção das notícias. Wolf (1985) chama atenção para a importância de trabalhos como o de White, que identifica pontos dentro de uma empresa de comunicação em que a notícia é rejeitada ou não, mas também já sinaliza fragilidades na concepção.

O mérito destes primeiros estudos foi o de individualizarem onde, em que ponto do aparelho, a acção de filtro é exercida explícita e institucionalmente. White analisa a actividade de gatekeeping no sentido específico de selecção; posteriormente, este tipo de pesquisa vem a conhecer duas fases, centradas no papel do aparelho como instituição social e numa abordagem sistemática. Por outras palavras, o carácter individual da actividade do gatekeeper é ultrapassado, acentuando-se, em particular, a ideia da seleç̧ão como processo hierarquicamente ordenado e ligado a uma rede complexa de feed-back (Wolf, 1985, p. 79).

Traquina (2005) tensiona ainda mais a questão ao levantar até que ponto a investigação deste filtro feito a partir da subjetividade do jornalista pode refletir a lógica do mercado industrial. O que corrobora para pensar os novos portões de entrada da notícia nos tempos atuais que considerem os interesses da empresa e os desejos da sua audiência.

A teoria do gatekeeper analisa as notícias apenas a partir de quem as produz: o jornalista. Assim, é uma teoria que privilegia apenas uma abordagem micro-sociológica, ao nível do indivíduo, ignorando por completo quaisquer fatores macro-sociológicos, ou mesmo, micro-sociológicos como a organização jornalística. (Traquina, 2005, p. 151)

1. "O conceito de gatekeeper (seleccionador) foi elaborado por Kurt Lewin, num estudo de 1947 sobre as dinâmicas que agem no interior dos grupos sociais, em especial no que se refere aos problemas ligados à modificação dos hábitos alimentares" (Wolf, 1985, p. 78). 
A produção do jornal analisado para este artigo chega a receber 20 mensagens por minuto. Esse número pode ser ainda muito maior, como conta a estagiária responsável pelo WhatsApp, Kallembach (2019): “Outro dia, ele [Rodolfo] pediu participação sobre valor do pão de sal e eu fiquei com umas 600/700 mensagens sem conseguir mexer no WhatsApp". Ao assumir a função de gatekeeper, ou seja, de filtrar as mensagens do WhatsApp, a estagiária pode ter a sensação de estar no controle dos assuntos e pautas que serão tratados no programa. Entretanto, o fato de o número de mensagens (texto, áudio e vídeo) que chegam por meio do aplicativo ser tão grande, também pode fazer com que este poder da apuração saia das mãos da jornalista e passe para as dos ouvintes da emissora.

Kallembach (2019) não esconde o poder dos ouvintes: "Eu sempre falo que eles são nossos olhos na rua. A gente não tem como estar em todos os lugares da cidade, então a gente tem os ouvintes para ver tudo". Para ela, muitas vezes são eles que "salvam a apuração" e sua presença onde ocorreu o fato basta para que a notícia seja veiculada. Esta relação de confiança estabelecida entre o jornalista e a sua audiência sugere um novo portão de entrada para a notícia: o zapkeeper.

O zapkeeper tem suas regras atreladas de alguma forma aos princípios básicos do jornalismo. Segundo a estagiária Kallembach (2019), por exemplo, na maioria das vezes a notícia só vai ao ar "porque são três ouvintes diferentes falando sobre o mesmo assunto". Lage (2001) ensina que para uma boa apuração de uma reportagem é preciso ouvir pelo menos três fontes totalmente distintas. "Toma-se como verdade, aí, o que é o mínimo comum aos três relatos, separando o que é fato do que é versão ou interpretação. $O$ testemunho singular (o que um viu e outro não) deve ter a fonte citada” (p. 29).

No dia a dia da BandNews FM, no entanto, esse distanciamento, que Kallembach (2019) aprende na teoria, não é aplicado. Muitas vezes, um único ouvinte é responsável pela pauta principal do dia. A edição do dia 11 de abril é um exemplo. Nesta manhã, o âncora Rodolfo Schneider começou o programa informando que havia troca de tiros na Alameda São Boa Ventura, em Niterói, cidade vizinha ao Rio de Janeiro. O jornalista não deu qualquer informação e pediu que a estagiária Kallembach (2019) trouxesse as mensagens recebidas pelo aplicativo WhatsApp. Ela de imediato avisou: "Um ouvinte que estava passando lá na hora mandou dois áudios para mim. Um do que ele estava 
vendo ali na região e depois ele conta dessa pessoa baleada. Vamos ouvir os relatos dele".

Neste momento, o zapkeeper entrou em ação, e as duas mensagens de áudio enviadas por Fábio, um ouvinte que passava de carro pelo local, foram colocadas no ar. Na primeira, ele faz o alerta de que há um tiroteio ocorrendo, mas não sabe bem onde:

Bom dia BandNews! Fábio Falando. Um tiroteio na Alameda. Todo mundo...eu tô vendo. Vou sair do carro. Tá todo mundo voltando, mas deu um tiroteio. Não sei bem, na altura de uma igreja do Fonseca, de uma Igreja Batista do Fonseca. Mais um tiroteio, bem. Vamos aguardar aí, o que tem mais a frente.

Na segunda, ele afirma que houve vítima.

Então, BandNews é teve gente baleada. Eu passei pelo local, perto da Caixa Econômica e a viatura da PM estava com uma pessoa baleada, talvez por bala perdida, algo assim, mas resgatando a pessoa. Bem eu já passei pelo acontecido já. Mas assim, sempre ter atenção quem tiver passando também.

A informação é fornecida pelo ouvinte sem responder efetivamente as clássicas e básicas perguntas: o quê, quem, como, quando, onde e por quê. A estagiária coloca no ar dois depoimentos que têm o olhar de quem passou e viu o fato, mas não parou para apurar o que ocorreu. Nota-se que neste processo coloca-se em risco um dos pilares do jornalismo, a apuração. De acordo com o artigo $4^{\circ}$ do Capítulo II, que trata exatamente sobre a conduta profissional do jornalista, do Código de Ética dos Jornalistas Brasileiros, “o compromisso fundamental do jornalista é com a verdade no relato dos fatos, razão pela qual ele deve pautar seu trabalho pela precisa apuração e pela sua correta divulgação" (Federação Nacional dos Jornalistas, 2007).

Apurar é diferente de ver, requer do profissional uma escuta atenta de todas as partes envolvidas na situação e o recolhimento do máximo de informação sobre o fato. Para tanto, ensina o mestre Nilson Lage, não basta ver o que está acontecendo. "A apuração, fundada no cultivo das fontes e nas entrevistas, parece insuperável. Tudo que se discute, na verdade, é ética - algo determinante mas externo ao processo produtivo" (Lage, 2001, p. 67). 
No caso do jornal analisado para este artigo, a notícia do dia continua a ser tratada pelos olhos dos ouvintes. A estagiária Julia Kallembach conta que recebeu "fotos dessa situação bem na frente das Lojas Americanas, e essa pessoa baleada teria sido levada para o Hospital Azevedo Lima, ali da região", mas continua sem dar uma informação oficial sobre o ocorrido. Ela ainda diz que há muitas pessoas querendo saber sobre outra situação que se passa na Barra da Tijuca, ou seja, algo que não tem nada a ver com a pauta mais importante do dia.

O assunto do tiroteio só volta depois de algum tempo quando a estagiária chama o âncora Rodolfo Schneider para dizer que, de acordo com o jornalista Gabriel Freitas, produtor do jornal, a Polícia Militar confirmou que levou uma pessoa baleada para o Hospital Azevedo Lima. A reação do âncora Rodolfo Schneider parece confirmar o poder do zapkeeper no "Jornal BandNews Rio - $1^{a}$ Edição". Para o jornalista, a participação do ouvinte é fundamental, principalmente, porque antecipa as fontes oficiais.

Como o nosso saudoso Ricardo Eugênio Boechat dizia, testemunha ocular da história. O Fábio viu toda a troca de tiros de dentro do carro, viu a pessoa baleada. Outro ouvinte mandou fotos, inclusive infelizmente com sangue no chão e relatando a mesma coisa. Antes mesmo da Polícia Militar confirmar essa informação pra gente eles relatavam o que estavam acontecendo. Agradecer a todos eles!

Quando o âncora do jornal parabeniza o ouvinte, ele legitima o poder de decidir o que e como colocar no ar uma notícia. Os dados prematuros, sem consistência e sem checagem, não são vistos como problema pelo profissional. Ele segue liderando o programa, falando sobre outros assuntos. Apenas uma hora mais tarde, finalmente, uma repórter entra com informações sobre a vítima no tiroteio de Niterói. A jornalista Taiana de Oliveira diz: "Luana Barbosa de Vasconcelos, de 21 anos, foi atingida na cabeça e está sendo operada. Informação passada pelo Corpo de Bombeiros". Foi o fim da história e do jornal.

\section{Newsmaking da audiência}

Depois de pensar a introdução de um zapkeeper, ainda com o exemplo citado em mente, é preciso refletir sobre a produção da informação ou, se preferir, a 
elaboração da notícia, o que metodologicamente cunhou-se de newsmaking (Wolf, 1985), na Era WhatsApp. A interação com ouvinte tornou-se peça-chave no noticiário da BandNews FM do Rio de Janeiro e o aplicativo WhatsApp a principal etapa da apuração. Os relatórios são feitos diariamente e, segundo a estagiária Kallembah (2019), chegam a registrar 50 mensagens por minuto.

Neste caso, coloca-se em xeque o que conceitualmente entende-se por newsmaking, na medida em que até então os estudos refletem as rotinas de produção que envolvem os profissionais de imprensa e as empresas de comunicação de massa. Wolf (1985) chama a atenção para o fato de que metodologicamente as pesquisas realizadas sobre newsmaking aplicam a técnica da observação participante e "desta forma, é possível reunir e obter, sistematicamente, as informações e os dados fundamentais sobre as rotinas produtivas que operam na indústria dos mass media" (p. 13). Acompanhando o pensamento de Wolf (1985), Aguiar (2014) afirma que a produção de notícias resulta de dois fatores:

De um lado, a cultura profissional, entendida com um emaranhado de estereótipos, representações sociais e rituais relativos às funções dos meios de comunicação de massa e dos jornalistas, às funções dos meios de comunicação de massa e dos jornalistas, à concepção do principal produto - a notícia - e às modalidades que presidem à sua confecção. De outro, as restrições ligadas à organização do trabalho, sobre as quais se criam convenções profissionais que determinam a definição de notícia, legitima o processo produtivo - desde a utilização das fontes até a seleção dos acontecimentos e as modalidades de confecção do noticiário - e contribuem para se prevenir das críticas dos leitores. Fica, assim, estabelecido um conjunto de critérios - ou seja, do grau de relevância entre os acontecimentos - que definem a noticiabilidade de cada acontecimento: o modo pelo qual é construída sua qualidade para que seja transformado em notícia (p. 226).

No momento em que as rotinas de produção jornalísticas estão sendo adaptadas às dinâmicas possibilitadas pelas novas tecnologias, que acabam por agregar efetivamente a participação direta, no caso da BandNews FM, do ouvinte a esta rotina, a elaboração de critérios de noticiabilidade torna-se quase impossível. Tomando o corpus analisado, os programas que foram ao ar de 8 a 12 de abril de 2019, principalmente a cobertura do dia 11 já tratada neste artigo, percebe-se que as mensagens enviadas pelos ouvintes pelo aplicativo WhatsApp os legitimam como testemunhas dos fatos e, consequentemente, os liberam para reportá-los. Na maioria das vezes, os ouvintes foram inseri- 
dos na programação para trazer alguma informação sobre o trânsito de determinada região da cidade.

No dia 9 de abril, por exemplo, o Rio de Janeiro vivia o caos causado por uma chuva intensa que começou no dia anterior. Desde o início da tempestade os testemunhos dos ouvintes da rádio BandNews FM tomaram conta da programação. A todo o momento as mensagens de áudio enviadas por WhatsApp eram colocadas no ar, o que dava uma sensação que elas não eram avaliadas previamente, que não havia um critério. Naquela manhã, foram os ouvintes que relataram a tragédia e orientaram sobre o trânsito. Ao todo, 14 mensagens foram colocadas no ar. No dia seguinte, a dinâmica foi a mesma. A pauta principal do jornal foi o rescaldo da chuva e, consequentemente, as duas mensagens que foram para o ar eram sobre os estragos causados pela tempestade $\mathrm{e}$ o caos que ficou o trânsito no Rio.

O que parece interessante pensar neste momento é como a "produção da notícia", "a construção dessa realidade", este newsmaking, que até então era dimensionado/estabelecido a partir de uma rotina industrial do veículo comunicação e da subjetividade do jornalista, ganha em alguns casos outro fator de intervenção. Na BandNews FM é possível pensar em um newsmaking da audiência: o ouvinte identifica e sugere o assunto, apura e reporta sem recorrer a qualquer critério de noticiabilidade. Por vezes, a seleção feita pelo cidadão que está nas ruas foi motivada pelo simples desejo deste ouvinte participar da produção do noticiário da rádio.

É fundamental ressaltar que o programa analisado responde a um trabalho de interação com público iniciado com o jornalista Ricardo Boechat, que morreu no início de 2019 em um acidente de helicóptero. Quando assumiu a emissora em 2005, Boechat mudou a forma de fazer radiojornalismo, porque passou a priorizar o cidadão à fonte oficial na cobertura da cidade do Rio de Janeiro. De acordo com o âncora Rodolfo Schneider, Boechat dizia: "Vamos inverter a lógica da notícia, que o prefeito fala, que o governador fala, que o presidente, o secretário, o ministro, a gente dá importância para isso como se isso fosse verdadeiro, e depois não acontece, não passa de uma promessa" (PUC Rio, 2019).

Boechat buscava, de certa forma, romper com o que se denominou jornalismo declaratório, "aquele jornalismo baseado nas declarações das fontes de infor- 
mação" (De Oliveira, 2018). Uma concepção muito usada, quando se analisa a produção de notícia feita a partir de notas oficiais apenas. Um jornalismo que não investiga, não ouve a população afetada pelos fatos e acaba depondo contra a profissão. "Enquanto a mídia continua pendurada na Esplanada dos Ministérios fazendo jornalismo declaratório de segunda mão, a vida acontece lá fora. Assim, com certeza, a mídia não reflete a opinião pública nem a opinião popular. Porque o jornalista está morto" (Adghirni, citado por De Oliveira, 2018).

Ao dar ao ouvinte da rádio o status de fonte principal, Boechat fortaleceu os laços da emissora com a audiência e criou uma nova dinâmica de trabalho para os apuradores. O testemunho do cidadão ganhou peso na construção da notícia, independentemente do assunto em pauta e, por vezes também, dos interesses comerciais da emissora. Colocar no ar o que o morador da cidade pensa sobre qualquer situação passa a ser percebido pelo público da emissora como mais importante que uma autoridade dos governos municipal e estadual.

Em outras palavras, a estratégia popularesca de falar por meio do testemunho do ouvinte é eficaz porque dialoga com o desejo do ouvinte de participar da escolha da notícia que vai ao ar. Ele quer ouvir a própria voz falando sobre a questões que afligem o cotidiano da sua cidade. Neste processo, com a autorização da equipe de jornalismo, o ouvinte participa ativamente do newsmaking da edição do jornal que ele acompanha diariamente. Ele está muito mais legitimado do que os primeiros cidadãos que enviaram conteúdo para a seção "VC Repórter" do Portal Terra, pioneiro no Brasil a instituir a participação do público (Aguiar e Barsotti, 2014, p. 4).

Neste caso a participação do ouvinte de certa forma reforça o que se chamou de jornalismo cidadão, colaborativo ou participativo, porque tem a tecnologia como aliada na sua forte atuação. "Os mais inovadores caminhos abertos pelas tecnologias digitais viraram o centro do picadeiro do jornalismo-cidadão" (Marshall, 2013). Mas o que chama mais atenção é que este cidadão pode estar alterando a rotina de produção do jornalista. Suas mensagens constituem testemunhos que, por vezes, substituem a ação do repórter ou, pelo menos, reduzem.

É possível pensar, ainda, que a autocomunicação de massa (Castells, 2015, p. 22), quando o cidadão produz e consome a informação que quiser, prática que a internet possibilitou, tenha chegado à audiência dos veículos tradicionais como rádio, que hoje também estão nas redes sociais. Afinal, 
o jornal analisado para este artigo é veiculado ao vivo na página da Rádio BandNews FM Rio de Janeiro no Facebook. Desta forma, a notícia produzida por este veículo de comunicação passa a circular além do dial 90,30 e fica disponível para todas aquelas pessoas que, atualmente, segundo Castells, têm uma relação de emoção com redes sociais e buscam nelas mais confirmação do que informação (YouTube, 2019).

\section{Considerações finais}

A participação do ouvinte na seleção da notícia que vai ao ar todas as manhãs no "Jornal BandNews Rio 1 a Edição" foi ampliada com a introdução do aplicativo WhatsApp na rotina de produção do jornalismo da Rádio BandNews FM Rio. Seja para informar sobre um congestionamento ou a denúncia de uma séria irregularidade praticada por uma autoridade. Sua participação ativa confirma a principal característica da nova configuração da comunicação no Século XXI: os papeis de emissor, receptor e canal não estão mais assim definidos. No jornalismo não é diferente.

O jornalista perdeu o status de "testemunha ocular da história", aquele que reportava a verdade dos fatos, do que ocorre no país e no mundo. Hoje, vivemos um momento em que a tecnologia transforma os modos de fazer e consumir comunicação, em que experimentamos o já mencionado fenômeno da "autocomunicação de massa". Um cidadão, de posse de um smartphone conectado à internet, está apto a ser agente ativo em qualquer um dos novos ecossistemas midiáticos. Neste sentido, o ouvinte da rádio está assumindo também seu novo papel neste cenário. Por meio de mensagens de áudio enviadas pelo aplicativo WhatsApp, ele passa a alimentar a produção da emissora como um repórter.

Ao fim de uma manhã, o número de mensagens pode ser tão grande que se abre mais um portão de entrada para a aprovação das notícias, o zapkeeper. Este novo portão sugere uma nova rotina de produção da informação, o newsmaking da audiência. A partir do desejo de participar da construção do no

2. “Testemunha Ocular da História” foi o slogan adotado pelo noticiário Repórter Esso (1941-1968), veiculado inicialmente pela Rádio Nacional do Rio de Janeiro e depois por diversas emissoras de rádio e televisão. 
ticiário, o ouvinte passa a narrar tudo que vê e entende como notícia. Seus critérios de noticiabilidade estão imergidos entre a razão e a emoção. Sem perceber, os ouvintes reproduzem o formato de jornalismo que se acostumaram a ouvir na rádio, acrescentando algo mais extremamente pessoal.

Este artigo não confirma como regra a existência de um novo "selecionador" de notícias, apenas sugere, porque a análise foi feita somente ao longo de uma semana no "Jornal BandNews Rio $1^{a}$ Edição". No entanto, os resultados instigam a realização de uma pesquisa mais aprofundada sobre o papel do WhatsApp como zapkeeper no jornalismo contemporâneo. Seu potencial é enorme.

\section{Referências}

Aguiar, L. (2014). Critérios de Noticiabilidade no Jornalismo Investigativo. En G. Silva, Da Silva, M. \& Fernandes, M. (Orgs.), Critérios de noticiabilidade - problemas conceituais e aplicações. Florianópolis: Insular.

Aguiar, L. \& Barsotti, A. (2014). Jornalismo amador: proposta para definir as práticas jornalísticas exercidas pelo público em ambientes interativos. Revista Pauta Geral-Estudos em Jornalismo, 1(1), 43-58.

Altman, F. (1995). A arte da entrevista: uma antologia de 1823 aos nossos dias. São Paulo: Scritta.

BandNews FM (2019a). Programação. Recuperado de https://bandnewsfmrio.com.br/Programacao

BandNews FM(2019b). Listas de reproducción. Recuperado de https://www. facebook.com/pg/bandnewsfmrio/videos/?ref=page_internal.

Bucci, E. (2000). Sobre Ética e Imprensa. São Paulo: Companhia das Letras.

Canavilhas, J. (2001). Webjornalismo: considerações gerais sobre o jornalismo na web. Recuperado de http://www.bocc.ubi.pt/pag/canavilhas-joao-webjornal.pdf. Acessado em 15 de junho de 2019. 
Canavilhas, J. (2010). O novo ecossistema mediático. Recuperado de http:// www.bocc.ubi.pt/pag/canavilhas-joao-o-novo-ecossistema-mediatico.pdf

Castells, M. (2003). A Sociedade em Rede. Rio de Janeiro: Paz e Terra.

Castells, M. (2015). O poder da Comunicação. Rio de Janeiro: Paz e Terra.

Charaudeau, P. (2013). Discurso das Mídias. São Paulo: Contexto.

Comassetto, L. (2007). O rádio local e o comportamento da informação na nova ordem global. Revista de Estudos da Comunicação, 8(16), 123-131 Recuperado de https://periodicos.pucpr.br/index.php/estudosdecomunicacao/article/view/14501/13901

Da Silva, L. Rocha, J. \& Pires, L. (2015). A participação do ouvinte no Jornal da CBN: uma análise sobre a utilização do aplicativo WhatsApp na construção do noticiário. Âncora - Revista Latino-americana de Jornalismo. 2(1), 116-137.

De Oliveira, I. (2018). O que é jornalismo declaratório? Recuperado de https://livro-reportagem.com.br/o-que-e-jornalismo-declaratorio

Federação Nacional dos Jornalistas (2007). Código de Ética dos Jornalistas Brasileiros. Recuperado de https://fenaj.org.br/wp-content/uploads/2014/06/04-codigo_de_etica_dos_jornalistas_brasileiros.pdf

Fernandes, B. (2011). A Teoria Clássica do Gatekeeper e do Newsmaking na Rádio: $O$ caso da RDP (informe de pasantía para obtener el grado de maestria em Periodismo). Universidade Da Beira Interior Artes e Letras, Covilhã. Recuperado de https://ubibliorum.ubi.pt/bitstream/10400.6/1311/1/Tese_Bruno_Fernandes.pdf

Globo.com (2019a). Homem morre após ser baleado em ação do Exército na Zona Oeste do Rio. Recuperado de https://g1.globo.com/rj/rio-de-janeiro/noticia/2019/04/07/homem-morre-apos-carro-ser-atingido-em-acao-do-exercito-na-zona-oeste-do-rio.ghtml 
Globo.com (2019b). Maior chuva em 22 anos no Rio causa 10 mortes, deixa bairros submersos e provoca destruição. Recuperado de https://g1. globo.com/rj/rio-de-janeiro/noticia/2019/04/09/bombeiros-registram-deslizamento-no-morro-da-babilonia-rio.ghtml

Globo.com (2019c). Cinco pessoas morrem em desabamento de prédios na Muzema, comunidade na Zona Oeste do Rio. Recuperado de https:// g1.globo.com/rj/rio-de-janeiro/noticia/2019/04/12/imovel-desaba-nazona-oeste-do-rio.ghtml

Kallembach, J. (7 y 11 de abril de 2019). Conversación por WhatsApp. Río de Janeiro, Brasil.

Lage, N. (2001). Teoria e técnica de reportagem, entrevista e pesquisa jornalística. Recuperado de http://nilsonlage.com.br/wp-content/uploads/2017/10/A-reportagem.pdf

Lewin, K. (1947). Frontiers in Group Dynamics: II. Channels of Group Life; Social Planning and Action Research. Recuperado de https://journals. sagepub.com/doi/pdf/10.1177/001872674700100201

Marshall, L. (2013). Novo Jornalismo? Jornalismo-cidadão assume controle do lead. Recuperado de http://observatoriodaimprensa.com.br/news/ view/_ed744_jornalismo_cidadao_assume_controle_do_lead

Pag Brasil (2019). Brasil: Os números do relatório Digital in 2019. Recuperado de https://www.pagbrasil.com/pt-br/insights/relatorio-digital-in-2019-brasil/

Pontifícia Universidade Católica do Rio de Janeiro, PUC Rio (28 de mayo de 2019). Palestra com Rodolfo Schneider, Ana Baum e Giovanni Faria. Recuperado de http://www.com.puc-rio.br/cgi/cgilua.exe/sys/start.ht$\mathrm{m}$ ?from $\% 5$ Finfo $\% 5$ Findex $=21$ \&infoid $=1347 \&$ sid $=24$

Resende, F. (2012). Falar para as massas, falar com o outro: valores e desafios do jornalismo. En V. França \& L. Corrêa (Orgs.), Mídia, instituições e valores (pp. 153-165). Belo Horizonte: Autêntica. 
Resende, F. \& Peres, A. (2016). Nós, as testemunhas: notas sobre um jornalismo de teor testemunhal. Revista Dispositiva, 5(2). Recuperado de http://periodicos.pucminas.br/index.php/dispositiva/article/ view/12694

Sodré, M. (2006). As estratégias sensíveis: afeto, mídia e politica. Petrópolis: Vozes.

Traquina, N. (2005). Teorias do Jornalismo. Porque as notícias são como são (vol. 1). Florianópolis: Insular.

We are Social (2019). Digital in 2019. Recuperado de https://wearesocial. com/global-digital-report-2019

White, D. (1993). O gatekeeper: uma análise de caso na seleção de notícias. En N. Traquina (Org.), Jornalismo: questões, teorias e estórias (pp. 142-151). Lisboa: Veja.

Wolf, M. (1985). Teorias da Comunicação. Lisboa: Presença.

YouTube (17 de julio de 2019). Palestra de Manoel Castells na FGV - Seminário Comunicação, Política e Democracia. Recuperado de https:// www.youtube.com/watch?v=yxxQhzH44xE 